\title{
Meshless, BE, FE and FD methods analysis of the flow and concentration in a water reservoir
}

\author{
K. Sakamoto ${ }^{1}$, M. Kanoh ${ }^{2} \&$ T. Kuroki ${ }^{3}$ \\ ${ }^{I}$ Environment Division, Matsue Doken Co., Ltd., Japan \\ ${ }^{2}$ Department of Civil Engineering, Kyushu Sangyo University, Japan \\ ${ }^{3}$ Baikoen, Japan
}

\begin{abstract}
In an earlier study, three methods, the meshless, the boundary element (BEM), and the weighted finite difference (WFDM) were developed to obtain numerically stable and convergent results for the concentration distribution and flow around a DO-supplying machine in a water reservoir. The poor-oxygen layer, which is short of or lacks dissolved oxygen (DO), sometimes causes pollution in the water in a reservoir. An attempt was made to ameliorate the concentration of oxygen in the lower layer of the reservoir by using a machine that supplies DO. Field studies in a few water reservoirs led to reports of a phenomenon in which the distance reached by the DO-rich water was more than 300 metres in spite of the very low velocity of the water flow. To numerically represent the phenomenon described above, we would like to investigate the numerical solutions of the meshless method, the BEM, the finite element method (FEM), and the finite difference method (FDM) and compare them with the observed results. With reference to the velocity vectors of the water flow calculated by the FDM, the BEM, and the FEM and observed in our model simulation described above, the effect and accuracy of the alternative meshless method were estimated.
\end{abstract}

Keywords: meshless method, boundary element method, finite element method, finite difference method, and flow and concentration in water reservoirs.

\section{Introduction}

By using a machine that supplies DO (dissolved oxygen), we successfully ameliorated the concentration of oxygen in the lower layer of water areas, such 
as a water reservoir or the sea (Sakamoto et al. [1]). Our DO-supplying machine dissolved the high concentration of oxygen (about $100 \mathrm{mg}$ per litre: $[\mathrm{mg} / \mathrm{L}]$ ) in the water of the tank of the machine at a depth of about 50 metres. The DO-rich water flowed out to the lower layer of the water area in a horizontal direction. The observed velocity of the water flow was considerably small (almost $0.1 \mathrm{~m} / \mathrm{sec}$ [metre per second]); however, the distance reached by the DO-rich water was observed to be more than 300 metres in the B reservoir. To obtain evidence to explain the phenomena, the model simulation of a water reservoir was investigated and newly reconstructed in our laboratory so that the observed results of the model simulation could represent the phenomena described above; in this way, we obtained some observed velocity vectors and the distributions of the DO concentration in the model. The analogy between the differences of the water temperature and the DO concentration was adopted and expected to reproduce the horizontal direction of the water flow and the convective diffusion of the DO of the water reservoir into our model simulation. The meshless method, the BEM, the FEM, the FDM, and the WFDM were newly investigated and applied to numerically simulate the phenomena. They were then compared with the observed data obtained in the model simulation.

\section{Governing equations}

Three equations, i.e., continuous, Navier-Stokes (N-S), and convective -diffusion equations, govern the flow and diffusion in a water reservoir. In the vertical ( $\mathrm{x}_{1}$, $\mathrm{x}_{2}$ ) plane, as illustrated in fig. 1, these equations are shown as follows:

$$
\begin{gathered}
\mathrm{u}_{1,1}+\mathrm{u}_{2,2}=0 \\
\dot{\mathrm{u}}_{1}+\mathrm{u}_{1} \cdot \mathrm{u}_{1,1}+\mathrm{u}_{2} \cdot \mathrm{u}_{1,2}-v\left(\mathrm{u}_{1,11}+\mathrm{u}_{1,22}\right)=-\mathrm{P},{ }_{1} / \rho \\
\dot{\mathrm{u}}_{2}+\mathrm{u}_{1} \cdot \mathrm{u}_{2,1}+\mathrm{u}_{2} \cdot \mathrm{u}_{2,2}-\mathrm{v}\left(\mathrm{u}_{2,11}+\mathrm{u}_{2,22}\right)=-\mathrm{P}, 2 / \rho+\mathrm{g} \\
\dot{\mathrm{C}}+\mathrm{u}_{1} \cdot \mathrm{C},_{1}+\mathrm{u}_{2}^{\prime} \cdot \mathrm{C},,_{2}-\mathrm{D}_{1} \cdot \mathrm{C},,_{11}-\mathrm{D}_{2} \cdot \mathrm{C},,_{22}=0 \\
\left.\rho=\rho_{0}+\mathrm{C}\right\rfloor 10^{-6}\left(1-\rho_{\text {DO }} / \rho_{0}\right)
\end{gathered}
$$

where $u_{1}$ and $u_{2}$ describe the velocities of the $x_{1}$ and $x_{2}$ directions, respectively, $P$ is the pressure, $\mathrm{g}$ is the gravity acceleration, $v$ is the kinematic viscosity, $\mathrm{C}$ is the concentration of dissolved oxygen (DO), and $\mathrm{D}_{1}$ and $\mathrm{D}_{2}$ are the diffusion coefficients of the $\mathrm{x}_{1}$ and $\mathrm{x}_{2}$ directions, respectively. Here, $\mathrm{C}_{,_{1}}$ and $\mathrm{C}_{2}$ describe the derivatives of $\mathrm{C}$ differentiated with respect to $\mathrm{x}_{1}$ and $\mathrm{x}_{2}$, respectively, $\mathrm{C},{ }_{11}$ and $\mathrm{C}_{22}$ are the derivatives of $\mathrm{C}$ differentiated twice with respect to $\mathrm{x}_{1}$ and $\mathrm{x}_{2}$, respectively. The density $\rho$ is connected to the DO concentration $\mathrm{C}$, as written in Equation (4), where $\rho_{0}$ and $\rho_{\mathrm{DO}}$ describe the densities of the pure water and the dissolved oxygen, respectively. The velocity $\mathrm{u}_{2}^{\prime}$, which is shown in the above Equation (3), is defined as written in Equation (5): 


$$
\begin{gathered}
\mathrm{u}_{2}^{\prime}=\mathrm{u}_{2}+\left(1-\rho_{\mathrm{DO}} / \rho_{0}\right) \rho g \mathrm{t}=\mathrm{u}_{2}+\alpha \mathrm{gt} \\
\mathrm{t}+\Delta \mathrm{t} \mathrm{u}_{2}^{\prime}={ }_{\mathrm{t}} \mathrm{u}_{2}+\alpha \mathrm{g} \Delta \mathrm{t} \text { in the finite difference expression }
\end{gathered}
$$

where ${ }_{\mathrm{t}+\Delta \mathrm{t}} \mathrm{u}_{2}^{\prime}$ and $\mathrm{u}_{2}$ are the velocities at time $(\mathrm{t}+\Delta \mathrm{t})$ and time $(\mathrm{t})$ in the vertical direction, respectively. The second term $(\alpha g \Delta t)$ of the right-hand side of Equation (5) means that the DO concentration increases the velocity of the vertical direction, and $\alpha$ describes the density of the liquid that dissolves DO. Here, the velocity increase is caused by the liquid density $\rho$, the gravity acceleration $g$, and the time increment $\Delta \mathrm{t}$. We expect that the velocity increase in the convective diffusion can be a device or evidence to explain the phenomenon in which the distance reached by the DO-rich water was more than 300 metres in spite of the very low velocity of the water flow.

\section{Application of the meshless method}

We applied the meshless method to a flow analysis in the steady state and a concentration analysis in the unsteady state in a water reservoir, as shown in fig. 1. The penalty method was used so that the pressure terms would be eliminated in the N-S equations and the difficulty of the pressure boundary conditions would be avoided in the meshless method (Sakamoto et al. [1]).

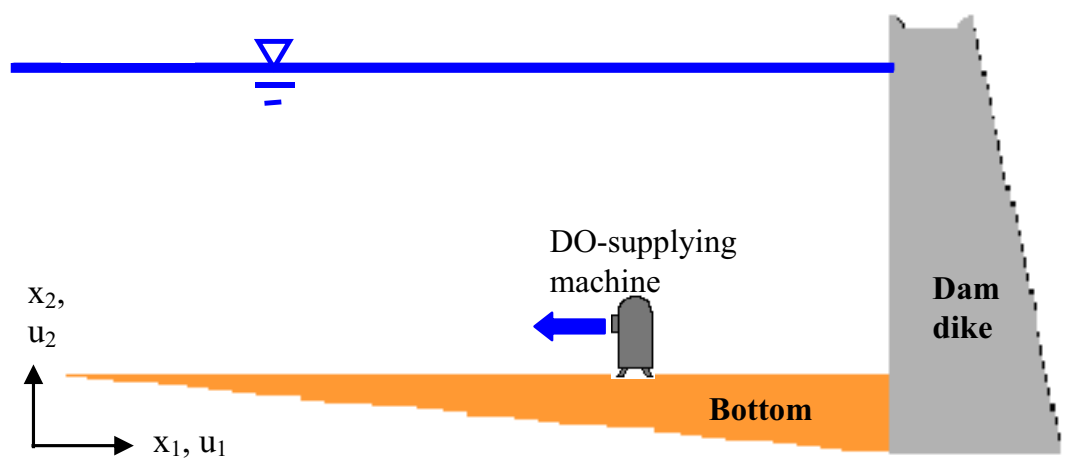

Figure 1: Analytical domain and concept of a DO-supplying machine in a water reservoir.

\subsection{Meshless method for flow and concentration analyses}

\subsubsection{Simultaneous equations for the meshless method of flow analysis}

Using $\underline{\mathrm{u}}_{1}$ and $\underline{\mathrm{u}}_{2}$ at time $(\mathrm{t}-\Delta \mathrm{t})$ and adopting the penalty method, the following expression is obtained (Kanoh et al. [2]):

$$
\underline{\mathrm{u}}_{1} \cdot \mathrm{u}_{1,1}+\underline{\mathrm{u}}_{2} \cdot \mathrm{u}_{1,2}-\lambda\left(\mathrm{u}_{1,11}+\mathrm{u}_{2,12}\right)-\mathrm{v}\left(\mathrm{u}_{1,22}+\mathrm{u}_{2,12}+2 \mathrm{u}_{1,11}\right)=0
$$




$$
\underline{\mathrm{u}}_{1} \cdot \mathrm{u}_{2,1}+\underline{\mathrm{u}}_{2} \cdot \mathrm{u}_{2,2}-\lambda\left(\mathrm{u}_{1,12}+\mathrm{u}_{2,22}\right)-\mathrm{v}\left(\mathrm{u}_{2,11}+\mathrm{u}_{1,12}+2 \mathrm{u}_{2,22}\right)=0
$$

where $u_{2,12}$ is the derivative of $u_{2,1}$ differentiated with respect to $x_{2}$. The unknown values $\mathrm{u}_{1}$ and $\mathrm{u}_{2}$ are expressed as Equation (7) using the global expansion function $\mathrm{Xj}\left(=\left(\mathrm{r}^{2}+\mathrm{c}^{2}\right)^{-1 / 2}\right)$ of the mesh-free RBF collocation method (Divo et al. [3]),

$$
\underline{\mathrm{u}}_{1} \cdot \mathrm{u}_{2,1}+\underline{\mathrm{u}}_{2} \cdot \mathrm{u}_{2,2}-\lambda\left(\mathrm{u}_{1,12}+\mathrm{u}_{2,22}\right)-\mathrm{v}\left(\mathrm{u}_{2,11}+\mathrm{u}_{1,12}+2 \mathrm{u}_{2,22}\right)=0
$$

where $\mathrm{r}$ equals $\left\{\left(\mathrm{x}-\mathrm{x}_{\mathrm{j}}\right)+\left(\mathrm{y}-\mathrm{y}_{\mathrm{j}}\right)\right\}^{1 / 2}$ and $\mathrm{c}$ is the constant. Solving the simultaneous Equation (8), the unknowns $\left(\alpha_{\mathrm{j}}\right.$ and $\beta_{\mathrm{j}}$ ) can be obtained.

$$
\begin{aligned}
& \left\{\left(\underline{u}_{1} \frac{\partial X_{j}}{\partial x_{1}}+\underline{u}_{2} \frac{\partial X_{j}}{\partial x_{2}}\right)-(v+\lambda) \frac{\partial^{2} X_{j}}{\partial x_{1}{ }^{2}}-v\left(\frac{\partial^{2} X_{j}}{\partial x_{1}{ }^{2}}+\frac{\partial^{2} X_{j}}{\partial x_{2}{ }^{2}}\right)\right\} \alpha_{j}-(v+\lambda) \frac{\partial^{2} X_{j}}{\partial x_{1} \partial x_{2}} \beta_{j}=0 \cdots \\
& -(v+\lambda) \frac{\partial^{2} X_{j}}{\partial x_{1} \partial x_{2}} \alpha_{j}+\left\{\left(\underline{u}_{1} \frac{\partial X_{j}}{\partial x_{1}}+\underline{u}_{2} \frac{\partial X_{j}}{\partial x_{2}}\right)-(v+\lambda) \frac{\partial^{2} X_{j}}{\partial x_{2}{ }^{2}}-v\left(\frac{\partial^{2} X_{j}}{\partial x_{1}{ }^{2}}+\frac{\partial^{2} X_{j}}{\partial x_{2}{ }^{2}}\right)\right\} \beta_{j}=0 \cdots
\end{aligned}
$$

Substituting the obtained values of $\alpha_{j}$ and $\beta_{\mathrm{j}}$ into Equation (7), the values of $u_{1}$ and $\mathrm{u}_{2}$ in the steady state can be calculated using the meshless method.

\subsubsection{Meshless method formulation for concentration analysis}

Here, we deal with the concentration analysis in the unsteady state in the area surrounding the DO-supplying machine. First, the concentration in the steady state is expressed as Equation (9) with Equation (10) (Kanoh et al. [2]).

$$
\begin{gathered}
\mathrm{C}=\gamma_{\mathrm{j}} \mathrm{Xj}=\beta_{\mathrm{j}} /\left(\mathrm{r}^{2}+\mathrm{c}^{2}\right)^{1 / 2} \\
\left\{\left(\underline{\mathrm{u}}_{1} \frac{\partial \mathrm{X}_{\mathrm{j}}}{\partial \mathrm{x}_{1}}+\underline{\mathrm{u}}_{2} \frac{\partial \mathrm{X}_{\mathrm{j}}}{\partial \mathrm{x}_{2}}\right)-\left(\mathrm{D}_{1} \frac{\partial^{2} \mathrm{X}_{\mathrm{j}}}{\partial \mathrm{x}_{1}{ }^{2}}+\mathrm{D}_{2} \frac{\partial^{2} \mathrm{X}_{\mathrm{j}}}{\partial \mathrm{x}_{2}{ }^{2}}\right)\right\} \gamma_{\mathrm{j}}=0
\end{gathered}
$$

Secondly, the transient convective-diffusion equation is rewritten as follows:

$$
\mathrm{C}_{\mathrm{t}}+\mathrm{L}(\mathrm{C})=0
$$

where $\mathrm{C}_{\mathrm{t}}$ is the time derivative of $\mathrm{C}$ and $\mathrm{L}(\mathrm{C})$ has the terms of convection and diffusion in the steady state. Thirdly, applying the finite difference scheme, Equation (11) yields

$$
\begin{aligned}
& \left(\mathrm{C}^{\mathrm{t}+\Delta \mathrm{t}}-\mathrm{C}^{\mathrm{t}}\right) / \Delta \mathrm{t}+\left\{\mathrm{L}^{\mathrm{t}+\Delta \mathrm{t}}(\mathrm{C})+\mathrm{L}^{\mathrm{t}}(\mathrm{C})\right\} / 2=0 \\
& \mathrm{C}^{\mathrm{t}+\Delta \mathrm{t}}+\mathrm{L}^{\mathrm{t}+\Delta \mathrm{t}}(\mathrm{C}) \cdot \Delta \mathrm{t} / 2=\mathrm{C}^{\mathrm{t}}-\mathrm{L}^{\mathrm{t}}(\mathrm{C}) \cdot \Delta \mathrm{t} / 2
\end{aligned}
$$

where $C^{t+\Delta t}$ and $C^{t}$ are the concentrations at time $(t+\Delta t)$ and time $(t)$, respectively, and $\mathrm{L}^{\mathrm{t}+\Delta \mathrm{t}}$ and $\mathrm{L}^{\mathrm{t}}$ are the terms of convection and diffusion at time $(\mathrm{t}+\Delta \mathrm{t})$ and time(t), respectively. Finally, using Equations (9), (10), and (13), the meshless method can analyse the DO concentration in the unsteady state. 


\subsection{Boundary conditions and boundary discretisation}

Both the boundary conditions and the boundary discretisation for the flow and concentration analyses have been previously proposed for the meshless method, the BEM, the FEM, the FDM, and the WFDM (Sakamoto et al. [1], Kanoh et al. [2]).

\section{Reconstructed model simulation}

We reconstructed a simulation model in our laboratory and obtained some observed velocity vectors and the distributions of the DO concentration in the model. In reference to the observed results, we tried to obtain some evidence to explain the phenomena that the distance reached by the DO-rich water was more than 300 metres in a reservoir in spite of the small velocity of the water flowing out. For this purpose, it was necessary to reproduce, in our model simulation, the density flow and convective diffusion of the DO concentration in the lower layer of a water reservoir at a depth of about 50 metres.

\subsection{Objective of the reconstruction and simulation technique}

There were two objectives in our reconstructed model and simulation technique. First, an outlet was set on the lower part of the left side wall of the model so that we could reproduce the horizontal direction of water flow of the lower layer of the water reservoir. Secondly, the density difference between $10 \mathrm{mg} / \mathrm{L}$ and 100 $\mathrm{mg} / \mathrm{L}$ in the DO concentration was changed to the density difference of the water temperature, since it was very difficult to make up the high concentration of DO of $100 \mathrm{mg} / \mathrm{L}$ in our model simulation at a depth of about 0.8 metres. Referring to Table 1, the density difference between $10 \mathrm{mg} / \mathrm{L}$ and $100 \mathrm{mg} / \mathrm{L}$ in DO was equal to the difference of the water temperature between 15 degrees centigrade $\left(15.00^{\circ} \mathrm{C}\right)$ and 14.55 degrees centigrade $\left(14.55^{\circ} \mathrm{C}\right)$. We iced the water that flowed out of the tank of the model and could easily control the difference of the water temperature between $15.00^{\circ} \mathrm{C}$ and $14.55^{\circ} \mathrm{C}$. The analogy between the

Table 1: Density difference between $100 \mathrm{mg} / \mathrm{L}$ and $30 \mathrm{mg} / \mathrm{L}$ in DO and that of the water temperature among $15.00,14.87$, and $14.55\left({ }^{\circ} \mathrm{C}\right)$.

\begin{tabular}{|c|c|c|}
\hline Place & $\begin{array}{c}\text { B water reservoir } \\
\text { (waterdepth:50m) }\end{array}$ & $\begin{array}{c}\text { Our model } \\
\text { simulation } \\
\text { (water depth:0.8m) }\end{array}$ \\
\hline Maximum DO value $(\mathrm{mg} / \mathrm{L})$ & 100 & 30 \\
\hline Water head $\left(\mathrm{Kg} / \mathrm{cm}^{2}\right)$ & 5.0 & 0.08 \\
\hline $\begin{array}{c}\text { Value of } \rho \\
\left.\text { (using Equation }(4): \text { at } 15^{\circ} \mathrm{C}\right)\end{array}$ & $0.999127+0.0001$ & $0.999127+0.00003$ \\
\hline $\begin{array}{c}\text { Water temperature that corresponds } \\
\text { to the above value of } \rho\left({ }^{\circ} \mathrm{C}\right)\end{array}$ & $\begin{array}{c}14.55 \\
(=15.0-0.45)\end{array}$ & $\begin{array}{c}14.87 \\
(=15.0-0.13)\end{array}$ \\
\hline
\end{tabular}


differences of the water temperature and the DO concentration was adopted and expected to reproduce the horizontal direction of water flow and the convective diffusion of the DO of the water reservoir into our model simulation.

Here, $5 \mathrm{Kg} / \mathrm{cm}^{2}$ (kilogram per square centimetre) corresponds to $0.5 \mathrm{MPa}$ (megapascal) in the international system of units (SI).

\section{Results and discussion}

As described above, we reconstructed a new simulation model in our laboratory and were able to observe some velocity vectors and obtain the distributions of the DO concentration in the model. In reference to the observed results, we tried to obtain some evidence to explain the phenomena that the distance reached by the DO-rich water was more than 300 metres in a reservoir in spite of the small velocity of the water flowing out. The numerical results of the meshless method, the BEM, the FEM, and the WFDM are also discussed in this section in order to obtain some evidence to explain the phenomena.

\subsection{Observed values in a model around a DO-supplying machine}

\subsubsection{Flow velocity in a model}

Fig. 2 is an illustration of the velocity vectors caused by a DO-supplying machine in a reservoir model visualised using aluminium flakes, a strobe light, and a digital VTR. In the area neighbouring the outflow point, the velocity vectors in the horizontal direction were distinguished, and the values of the velocities were larger than those in other areas. In other areas, which were toward the centre or more than 0.9 metres from the outflow point, the velocity values became less than $1 \mathrm{~cm} / \mathrm{sec}$.

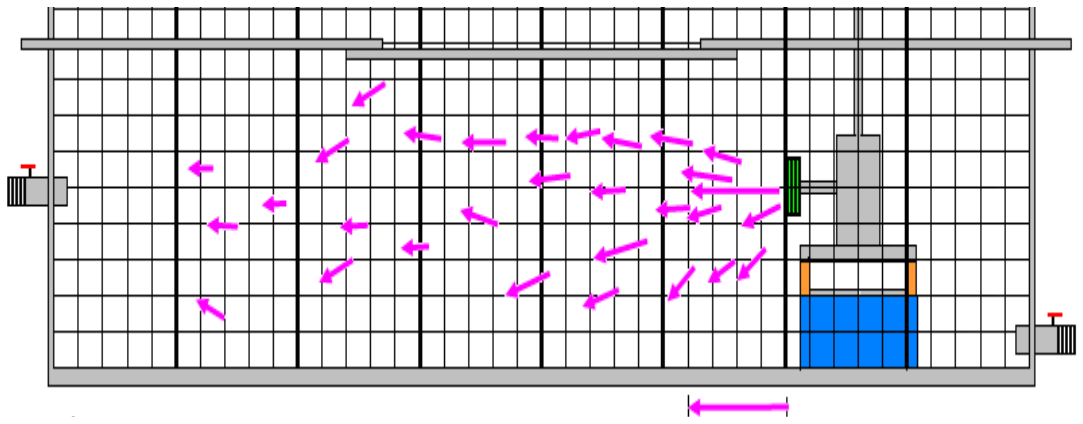

Figure 2: Observed velocity vectors around a DO-supplying machine (DO: $30 \mathrm{mg} / \mathrm{L})$.

\subsubsection{Concentration distribution of DO in a model}

Fig. 3 is an illustration of the concentration distribution caused by a DOsupplying machine in a reservoir model visualised using a pigment (methylene 
blue) and a VTR. The speed of diffusion of the DO-rich water (DO: 100mg/L) was obviously quicker than that in DO-poor water (DO: $10 \mathrm{mg} / \mathrm{L}$; the figure was omitted in this paper), and the observed direction of the diffusion was mainly down or horizontal.

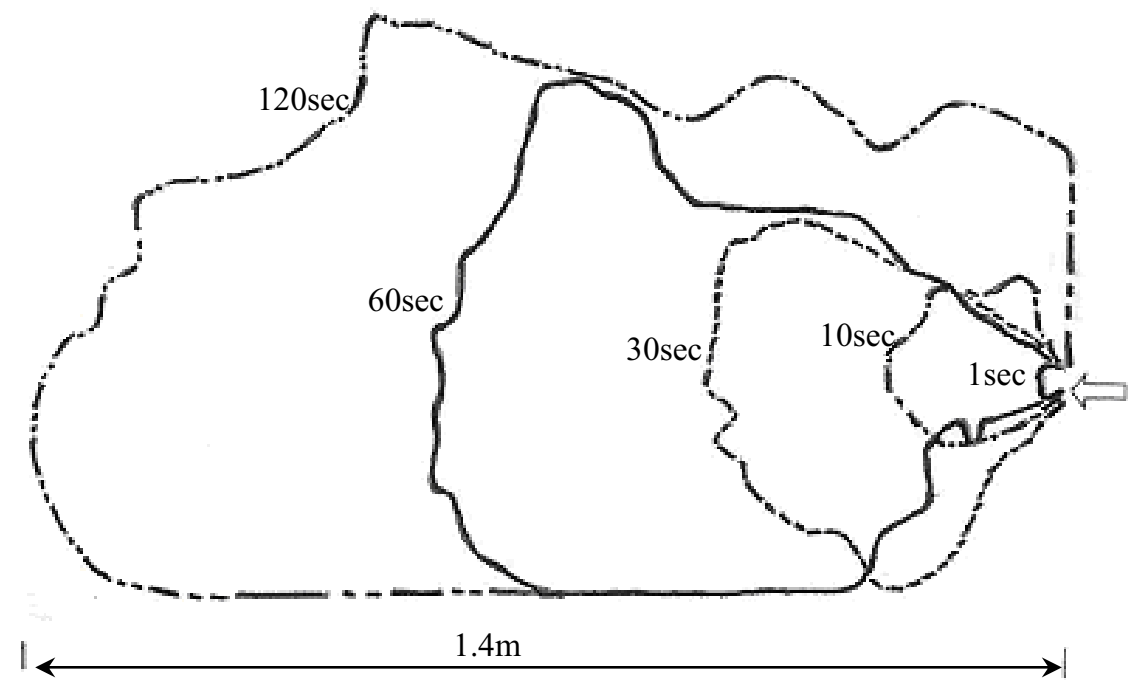

Figure 3: $\quad$ Observed areas of diffusion of pigment (DO: $100 \mathrm{mg} / \mathrm{L}$ ).

\subsection{Flow analysis in the model of a water reservoir}

\subsubsection{Meshless method calculation of the flow in the model}

Fig. 4 is an illustration of the velocity vectors in the model of a water reservoir calculated by the meshless method, in which the number of the points in the meshless method is 3,201 and the three values of $\lambda, \mathrm{C}$, and $v$ are 1,000.0, 1.0, and 0.001 , respectively. The stability and convergence of the flow analysis around the machine to supply DO using the meshless method seemed satisfactory.

\subsubsection{FEM, BEM, and FDM calculation of the flow in the reservoir model}

Fig. 5 is an illustration of the velocity vectors in the reservoir model calculated by the FEM, in which the number of elements in the FEM is 3,072 and the two values of $\lambda$ and $v$ are $1,000.0$ and 0.001 , respectively. The penalty method was introduced, as in the meshless method. The stability and convergence of the flow analysis using the FEM seemed satisfactory. The stability and convergence of the flow analysis using both the BEM and the FDM also seemed satisfactory (the figures to illustrate those velocity vectors have been omitted). These three methods could yield qualitatively similar solutions to the true results of several flow problems that were observed in simulation models constructed in our laboratory. 


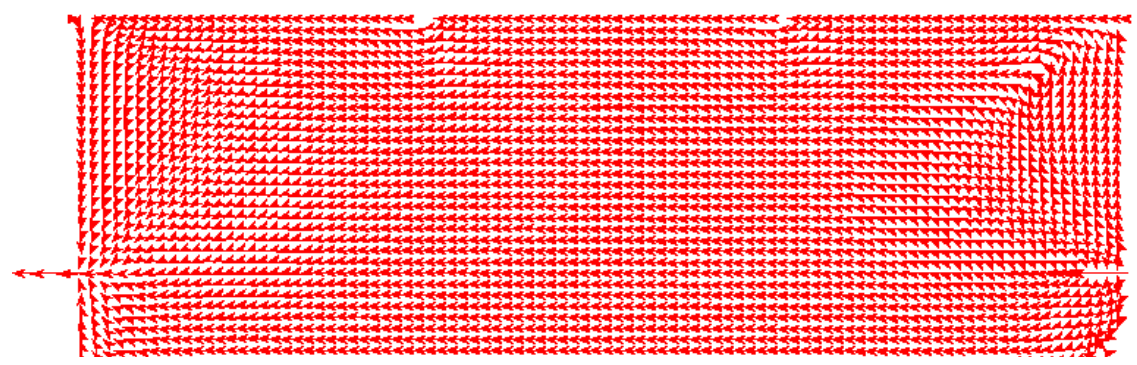

Figure 4: Velocity vectors using the meshless method (number of the points: 3,201).

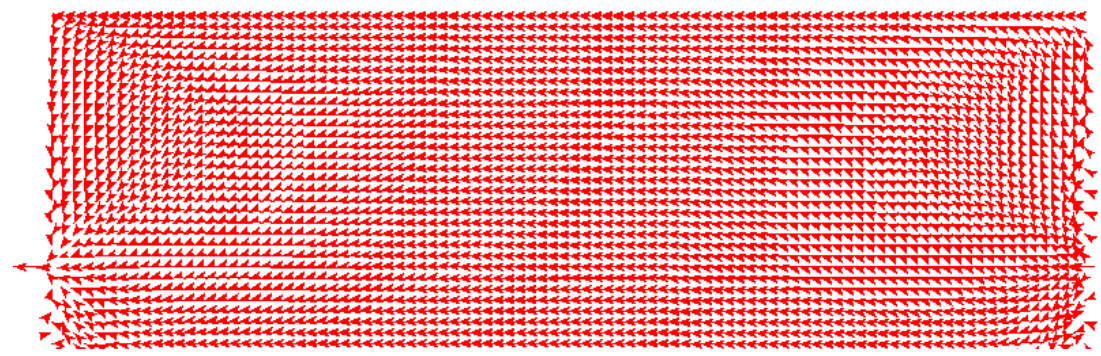

Figure 5: Velocity vectors using the FEM (number of the points: 3,201).

\subsection{DO concentration analysis in the model of a water reservoir}

\subsubsection{Time required by the four numerical methods for the DO analysis}

Table 2 shows the time required by the four numerical methods for analysing the DO concentration in the model. When the number of the divisions of the analytical domain was 3,201, the FDM, the BEM, and the meshless method needed almost 7, 10, and 6 times the time required for the FEM, respectively. For the purposes of saving time, the FEM was the best; the meshless method was second best; the FDM was the third best; and the BEM was the poorest performer. On the other hand, for the purpose of saving the time and labour required for preparing the input data, the meshless method was the best, the FDM was second best, the FEM was the third best, and the BEM was the worst.

\subsubsection{FEM calculation of the concentration distribution}

Figs. 6(a) and (b) are illustrations of the concentration distribution calculated using the FE method, in which the number of divisions in the FEM is 3,201 and the two values of $\lambda$ and $v$ are $1,000.0$ and 0.001 , respectively. Comparing fig. 6(a) (not adopting the term: $\alpha g \Delta t$ ) with fig. 6(b) (adopting the term: $\alpha g \Delta t$ ), it was noted that the term $(\alpha \mathrm{g} \Delta \mathrm{t})$ of the velocity increase brought the areas of the DO distribution down in the FEM analysis. 
Table 2: $\quad$ The time required by the four methods for analysing the unsteady convective diffusion of DO for 60 seconds in a model of a water reservoir.

\begin{tabular}{|c|c||c|}
\hline Rumerical method & $\begin{array}{c}\text { Number of divisions: } \\
3,201\end{array}$ & $\begin{array}{l}\text { Time } \\
\text { increment: } \\
\Delta \mathrm{t}(\mathrm{sec})\end{array}$ \\
\hline FEM & 1.00 & 0.1 \\
\hline FDM & 7.00 & 1.0 \\
\hline BEM & 10.1 & 1.0 \\
\hline Meshless method & 6.03 & 20 \\
\hline
\end{tabular}

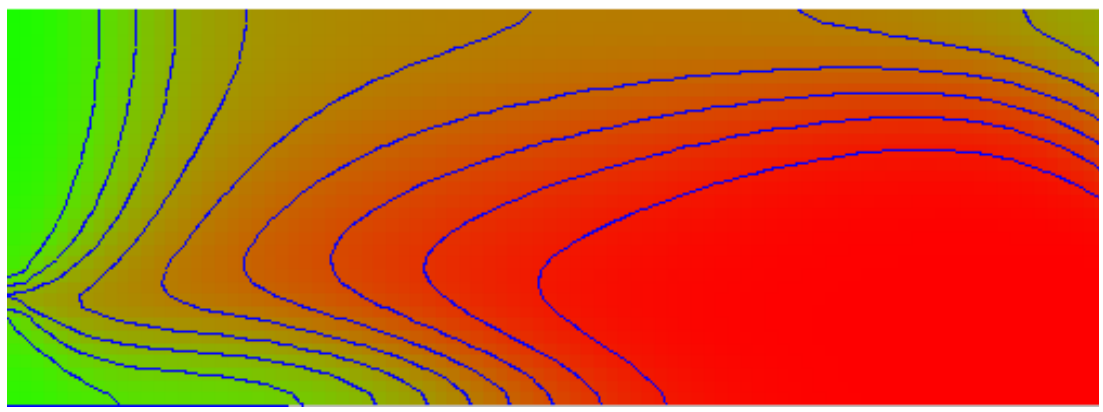

(a)

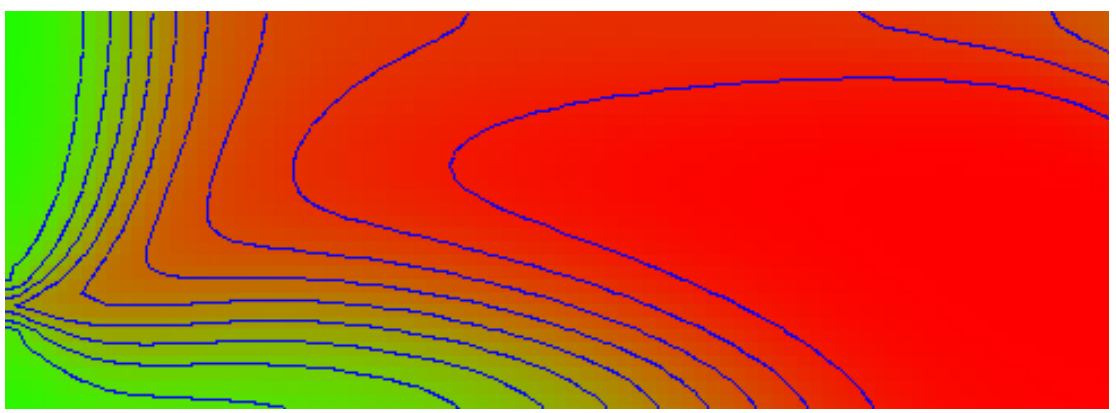

(b)

Figure 6: (a) DO-concentration distribution calculated using the FEM without the term $(\alpha \mathrm{g} \Delta \mathrm{t}) \quad[\mathrm{t}=420 \mathrm{sec}]$. (b) DO-concentration distribution calculated using the FEM with the term $(\alpha g \Delta t)$ $[\mathrm{t}=420 \mathrm{sec}]$.

\subsubsection{Meshless calculation of the concentration distribution}

Fig. 7 is an illustration of the concentration distribution calculated using the meshless method, in which the term of the velocity increase $(\alpha \mathrm{g} \Delta \mathrm{t})$ is adopted, 
the number of divisions in the meshless method is 3,201, and the value of $v$ is 0.001 (the figures to illustrate the concentration distribution calculated without the term $(\alpha g \Delta t)$ have been omitted). Referring to figs. 6 and 7, the solutions of the meshless method showed the same tendency as those of the FEM in this problem. We considered that the convergence and accuracy of the FE, the FD, the $\mathrm{BE}$, and the meshless methods for this problem were satisfactory (the figures to illustrate the concentration distribution calculated using the FD and the BE methods have been omitted).

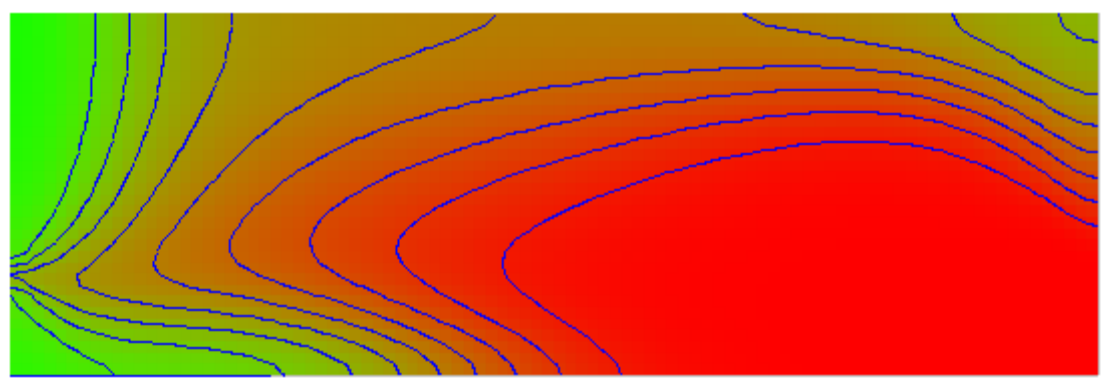

Figure 7: DO-concentration distribution using the meshless method with the term $(\alpha \mathrm{g} \Delta \mathrm{t})[\mathrm{t}=420 \mathrm{sec}]$.

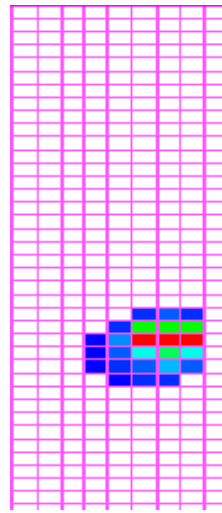

$\mathrm{t}=1 \mathrm{sec}$

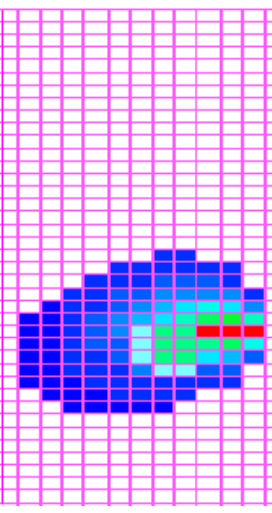

$\mathrm{t}=10 \mathrm{sec}$

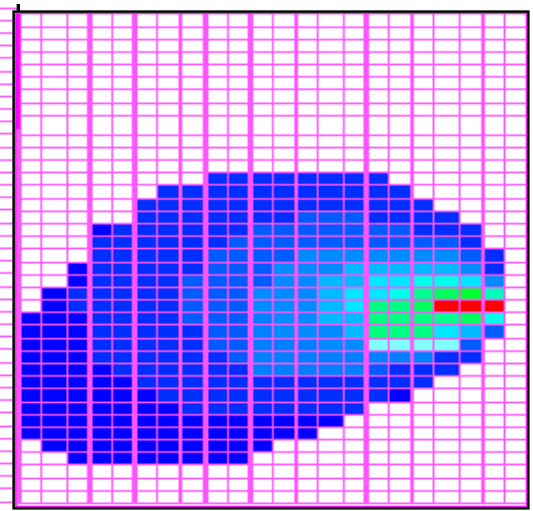

$\mathrm{t}=60 \mathrm{sec}$

Figure 8: DO-concentration distribution using the WFDM with the term $(\alpha g \Delta t)$.

\subsubsection{WFDM calculation of the concentration distribution}

Fig. 8 is an illustration of the concentration distribution calculated using the

WFDM, in which the term of the velocity increase $(\alpha g \Delta t)$ is adopted, the number 
of divisions in the WFDM is 25,600 , and the value of $v$ is 0.001 (the figures to illustrate the concentration distribution calculated without the term $(\alpha \mathrm{g} \Delta \mathrm{t})$ have been omitted). We considered that the convergence and accuracy of the WFDM for this problem were satisfactory. It seemed that the term $(\alpha \mathrm{g} \Delta \mathrm{t})$ of the velocity increase could make the areas of the diffusion wider in the vertical and flowingout directions and the speed of the convective diffusion higher than in the analyses of the WFDM when this velocity increase was not applied.

\section{Conclusion}

In summary, (1) the meshless method, the BEM, the FEM, the FDM, and the WFDM were newly investigated and applied to the analysis of the flow and convective diffusion in a water reservoir; (2) the stability and convergence of the five kinds of analysis using these methods described above seemed satisfactory; (3) in this paper, it was proposed that the DO concentration increased the velocity of the vertical direction, where the velocity increase was caused by the water density $\rho$, the gravity acceleration $g$, and the time increment $\Delta t$; (4) the velocity increase could make the areas of the diffusion wider in the vertical and outflow directions and make the speed of the convective diffusion be higher than in the analyses of these methods when this velocity increase was not applied; (5) the analogy between the differences of the water temperature and the DO concentration was adopted and expected to reproduce the horizontal direction of the water flow and the convective diffusion of the DO of the water reservoir into our model simulation; (6) it seemed that the wide areas of diffusion and quick speed of convective diffusion could explain the phenomena in which the distance reached by the DO-rich water was more than 300 metres in spite of the very low velocity of the water flow.

\section{References}

[1] Sakamoto, K., Kanoh, M., \&. Kuroki T., Meshless and BE analysis of flow and concentration around a DO-supplying machine, Proc. of the $30^{\text {th }}$ World Conf. on Boundary Elements and Other Mesh Reduction Methods, ed. C.A. Brebbia, WIT PRESS, Maribor, Slovenia, pp. 23-32, 2008.

[2] Kanoh, M., Nakamura, N., Kuroki T., \& Sakamoto, K., Meshless analysis of flow and concentration in a water reservoir, Proc. of the $29^{\text {th }}$ World Conf. on Boundary Elements and Other Mesh Reduction Methods, ed. C.A. Brebbia, WIT PRESS, Southampton, UK, pp. 169-178, 2007.

[3] Divo E., Kassab A., and Zahab El., Parallel domain decomposition meshless modeling of dilute convection-diffusion of species, Proc. of $27^{\text {th }}$ World Conf. on Boundary Elements and Other Mesh Reduction Methods, ed. C.A. Brebbia, WIT PRESS, Florida, USA, pp.79-89, 2005. 